\title{
Numerical simulation of subsynoptic-scale cyclogenesis around an idealized antarctic continent
}

\author{
Simulación numérica de ciclogénesis a escala subsinóptica \\ alrededor de un continente antártico idealizado
}

Jorge F. Carrasco ${ }^{1}$

\begin{abstract}
A three-dimensional numerical model of 100$\mathrm{km}$ horizontal resolution was used to simulate subsynoptic-scale cyclogenesis around an idealized Antarctic continent. The simulation resolved a series of subsynoptic-scale cyclones around the idealized continent. These cyclones form adjacent to the confluence zones of katabatic winds. Their movements indicate an eastward direction going away from their initial point of formation. Baroclinic instability appears as primary mechanism for the development of these cyclones.
\end{abstract}

\section{Key words:}

numerical model, katabatic winds,

subsynoptic-scale, cyclones, instability.

\section{Resumen}

Un modelo numérico tridimensional de $100 \mathrm{~km}$ de resolución horizontal, fue utilizado para simular ciclogénesis a escala subsinóptica alrededor de un continente antártico idealizado. La simulación resuelve una serie de centros depresionarios alrededor del continente idealizado. La formación de los ciclones ocurre adyacentes a las zonas de convergencia del flujo de vientos catabáticos. $\mathrm{Su}$ desplazamiento indica una dirección al este alejándose de su área de formación inicial. La inestabilidad baroclínica aparece como mecanismo primario para el desarrollo de estos ciclones.

\section{Palabras clave:}

modelo numérico, vientos catabáticos, escala subsinóptica, ciclones, inestabilidad.

\section{INTRODUCTION}

Articles about observational studies of subsynoptic-scale cyclones (those with a diameter less than $1000 \mathrm{~km}$ ) in high southern latitudes indicate that these cyclonic perturbations can be observed at any longitude or latitude near the edge or over the sea ice zone, near the coastal margin of the Antarctic continent, and over the continental interior (Carrasco et al. 2003; Uotila et al. 2011; Pezza et al. 2015). Moreover, the spatial seasonal and annual distribution of subsynotic cyclones revealed larger activity near the katabatic confluence zones (Carrasco and Bromwich, 1996; Carrasco et al. 1997a, b; Turner et al. 1996; Carrasco et al. 2003). On the other hand, the Antarctic topography has a large influence on the atmospheric circulation around the continent, and thereby indirectly on the preferred locations of regions of cyclogenesis (Walsh et al. 2000).

The broadscale topographic structure of the Antarctic continent is the primary factor causing the descending airflow to converge into several zones near the steep coast of the continent (Parish \& Bromwich, 1987). As individual case studies have revealed, the katabatic wind outbreak of cold antarctic air mass interacts with warmer air offshore of the costal margin, creating low-level baroclinic zones that set up

\footnotetext{
1 Universidad de Magallanes, Punta Arenas-Chile.

$\checkmark$ jorge.carrasco@umag.cl
} 
conditions for subsynoptic-scale cyclogenesis (e.g., Bromwich, 1989a, Carrasco \& Bromwich, 1993a; Turner et al. 1993a; Heinemann, 1996; Klein \& Heinemann, 2001; Heinemann \& Klein, 2003).

Therefore, studies indicate that katabatic airflow are the primary precursor for subsynopticscale cyclogenesis near the confluence zone where these cold-descending winds converge into several tropospheric troughs around Antarctica. Here a three-dimensional numerical model (Parish \& Waight, 1987; Parish \& Bromwich, 1991) was used to determine the precise role of the katabatic winds in subsynoptic cyclogenesis. The model (PW model, hereafter) was a much simplier version than modern regional models like the Antarctic Mesoscale Prediction System (AMPS, Powers et al. 2003) and the Polar Weather Research and Forecasting (PWRF) (Bromwich et al. 2013). This earlier versión of subsynoptic-regional model allowed simulating the near-surface circulation as a result only of the radiative forcing given by the surface cooling of the continent, and it allowed exploring the role of the katabatic winds in subsynoptic cyclone formation. To simplify even more the complexity of the Antarctic continent, the simulation was run with a $60 \times 60$ gridpoint of an idealized Antarctic terrain heights at a $100 \mathrm{~km}$ resolution, and for 20-days model integration. The horizontal and vertical resolutions were appropiated for simulating the near-surface katabatic winds and subsynopticscale circulation around Antarctica. The idealized continent was a dome of about $4200 \mathrm{~km}$ diameter with a plateau at $3800 \mathrm{~m}$ of elevation dissected by topographic troughs longitudinally-oriented (see Fig. $1 \mathrm{~d}$ and 2). Once again, the idealized terrain allowed examination of some aspects of the atmospheric dynamics without the complications introduced by the complexity of the real terrain. Next section briefly describes the PWmodel and procedure used for the simulations. Section 3 presents the results, while discussion and conclusions are included in Section 4.

\section{MODEL DESCRIPTION} AND METHODOLOGY

A three-dimensional version of the numerical model described in Parish and Waight (1987) was used (Appendix 1). The model was a modified form of that presented in Anthes and Warner (1978) and included prognostic equations for horizontal momentum components ( $\mathrm{u}$ and $\mathrm{v}$ ), temperature and continuity of mass. The model grid was of cartesian form with a variable Coriolis parameter. To allow for inclusion of the ideliazed Antarctic topography, all equations were written in a modified sigma coordinates where the vertical coordinate was defined as:

$$
\sigma=\frac{p-p_{t}}{p_{s}-p_{t}}=\frac{p-p_{t}}{p^{*}}
$$

Where $p_{\mathrm{t}}$ is the pressure at the top of the model and $p_{\mathrm{s}}$ is the surface pressure. The implementation of the model on sigma coordinates is particularly useful around and near the continent because of the high topography of Antarctica (Walsh et al. 2000).

The model employed open boundary conditions in which mass and energy were permitted to leave the model domain. Prognostic variables were extrapolated outward to the boundaries to help to reduce spurious reflections. The modeling efforts utilized a sixlevel bulk layer version (sigma levels 0.98, 0.95, $0.85,0.60,0.35,0.10)$ in which the entire planetary boundary layer (BL) was represented by the first single layer and fluxes of momentum and heat were related to the conditions at the surface. The BL height was set at approximately $125 \mathrm{~m}$ and corresponds to the top of the first sigma level. Parameterizations for $\mathrm{BL}$ radiative and turbulent fluxes were based on the results obtained from the full numerical model where these effects were explicitly modeled (see Parish and Waight, 1987). A net cooling rate of the BL near the coast was estimated about 100 $\mathrm{Wm}^{-2}$, which decreased by approximately onethird over the interior, following results found by Parish and Waight (1987). The larger cooling rate of the $\mathrm{BL}$ near the coast was caused by the downward turbulent heat flux associated with stronger katabatic winds over the steep coastal slopes. Here, cooling rates of $110 \mathrm{Wm}^{-2}$ near the coast and $60 \mathrm{Wm}^{-2}$ over the interior were specified.

The bulk model offered a convenient means of providing results comparable with 

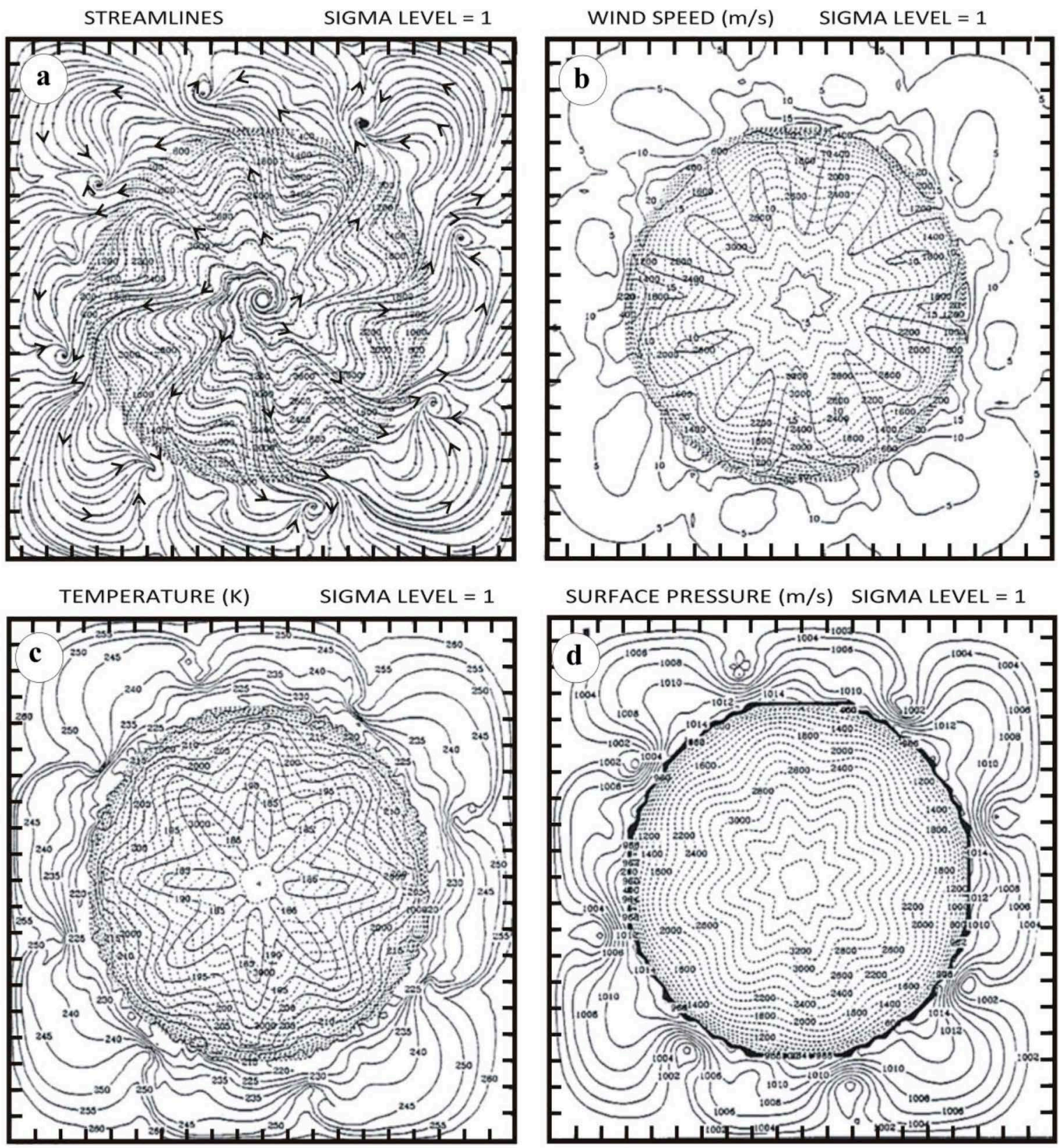

SURFACE PRESSURE $(\mathrm{m} / \mathrm{s})$ SIGMA LEVEL $=1$

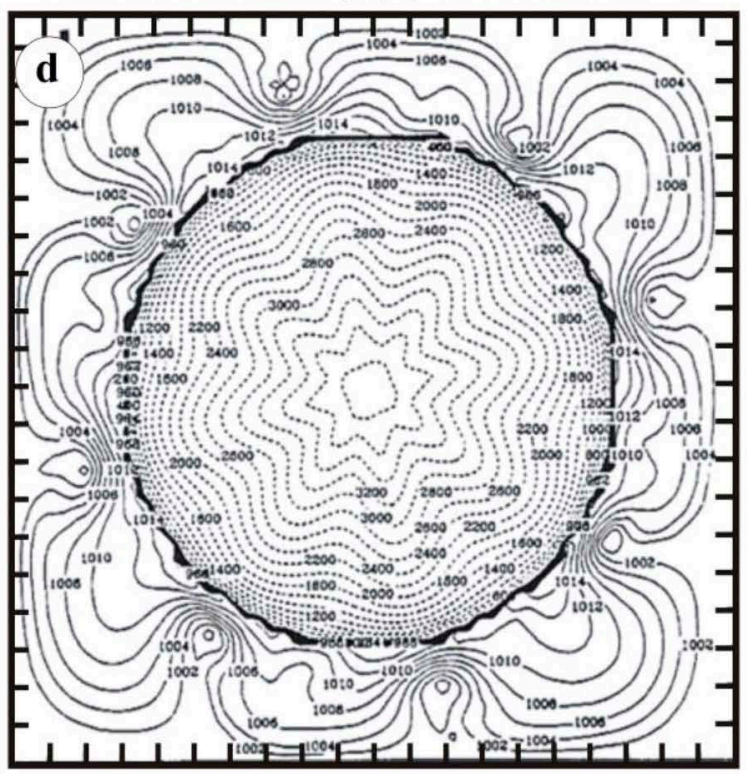

Fig. 1. a) Streamlines, b) wind speed $\left(5 \mathrm{~ms}^{-1}\right.$ interval), c) temperature (K) and d) surface pressure at the first sigma level after 10 days model simulation. Separation of the bars is $300-\mathrm{km}$.

the more refined approach without excessive computational demands. The simulation examines the winter cloud-free conditions of the simulated Antarctic dome with no influence of solar radiation. However, an open ocean surface off the continental dome with constant surface temperature of the ocean throughout the integration was used in the model. Parish (1992) found that the evolution and intensity of the downslope component of the katabatic wind for Antarctica surrounding by ocean does not significantly differ from that of an Antarctica 


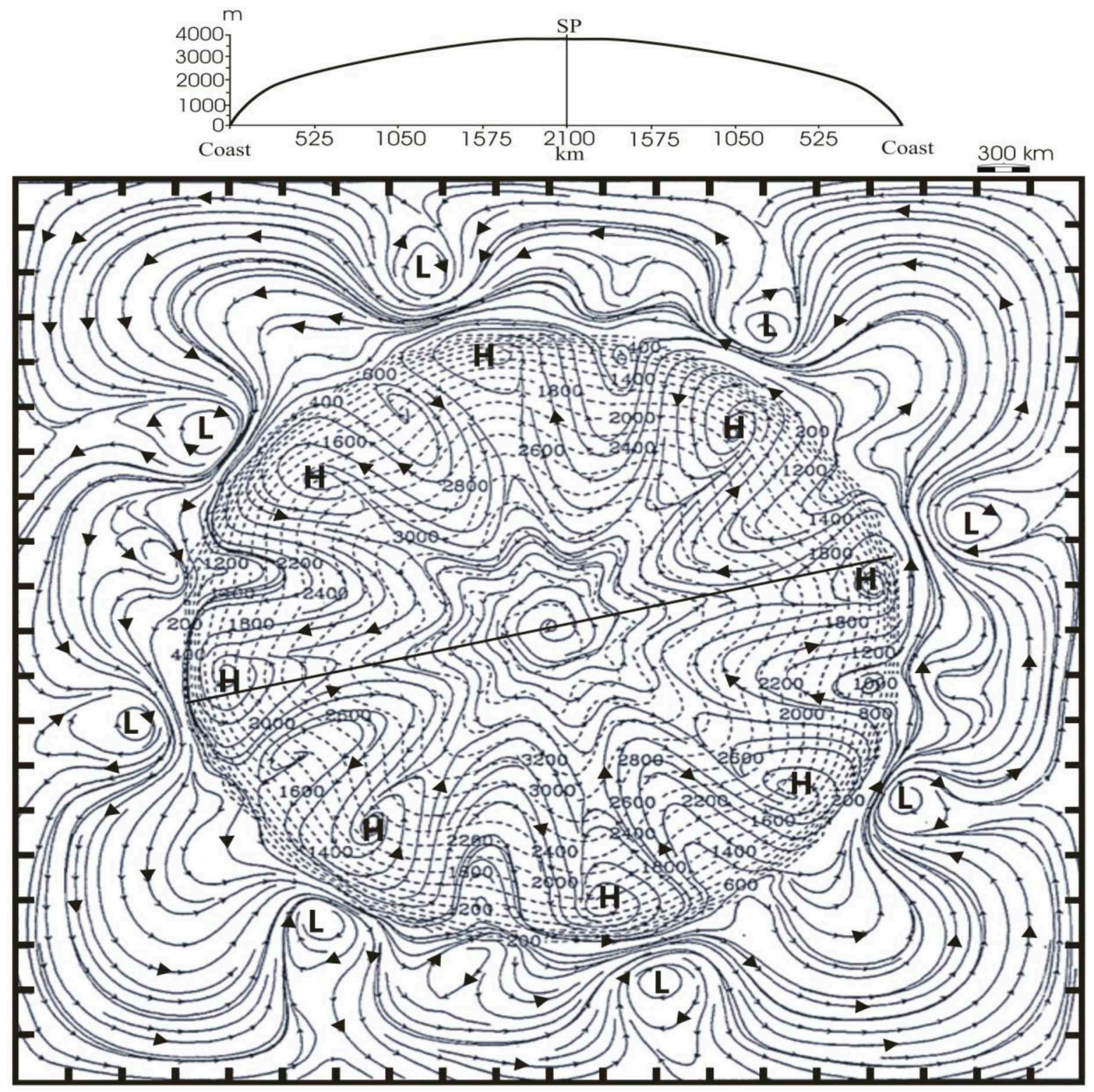

Fig. 2. Streamlines at the second sigma level (about $300 \mathrm{~m}$ above the surface) after 10 days model simulation using a 100-km resolution with idealized Antarctic terrain. L: low pressure, $\mathrm{H}$ : high pressure. On the top, orographic profile of the idealized Antarctic model along the line drawn on the continent.

surrounding by sea ice. However, the northsouth thermal contrast is stronger with open ocean. This implies that the major effect of the above is to accelerate the development of the baroclinic nature of the coastal environment of Antarctica and, therefore, cyclogenesis processes. Simulation was initialized from a state of rest, which ensures that the topographic motions arise as a result of the radiative cooling of the model ice slopes and subsequent evolution of the katabatic winds. The use of this model was to simulate complex processes in a simplified manner but keeping the physic and dynamic behind the development of the katabatic winds, baroclinic zones and subsynoptic cyclogenesis formation. 


\section{RESULTS}

The Figures 1a-d are the results of the idealized Antarctic continent showing the streamlines, wind speeds $\left(\mathrm{m} \mathrm{s}^{-1}\right)$ and temperature at the first sigma level (about $100 \mathrm{~m}$, the $\mathrm{BL}$ ) and the surface pressure, after 10 days of model integration. It can be seen that the model resolved eight cyclonic circulations near the confluence zones of katabatic winds around the continental dome. The resolved low pressure centers (see Fig. 1d) are located on the open ocean just to north of the maximum katabatic winds area that take place over the steep slopes of the idealized continent. Note that there is one subsynoptic low (see the pressure perturbation in Fig. 1d) per each orographic trough. A strong temperature gradient zone (front-like feature, see Fig. 1c), is associated with each of the cyclonic circulation indicating the encounter of the descending cold katabatic air (to the southwest) and the warmer air originating over the open ocean (to the east). These cyclonic circulations vertically extend up to some where between the second and third sigma levels (below $1000 \mathrm{~m}$ ) with a slight poleward tilt. Fig. 2 shows the streamlines at the second sigma level (300 $\mathrm{m}$, above the simulated boundary layer) revealing a more complex circulation over the continent. Above this level the westerly regime dominates with the development of a polar vortex centered over the idealized terrain. Previous works of katabatic wind regime simulation in Antarctica (Parish \& Bromwich, 1991; Parish, 1992) has shown that the strong temperature gradient around the margin of the simulated continent was concentrated in the lowest levels of the simulated atmosphere, here it was well developed below the third sigma level (about $1000 \mathrm{~m}$ ).

The evolution of the streamlines, wind speeds and temperature at the first sigma level from day one to day eight of the model simulation is shown in Figs. 3a-d to 5a-d. Results indicate that the katabatic wind drainage rapidly developed being over $15 \mathrm{~m} \mathrm{~s}^{-1}$ around the steep coast after $24 \mathrm{~h}$ simulation (Figs. $3 \mathrm{a}$ and $4 \mathrm{a}$ ). Also, at this time and to the north from the coast, a convergence zone seems to develop with easterly winds to the south and westerly to the north (Fig. 3a). Maximum wind speeds of $25 \mathrm{~m} \mathrm{~s}^{-1}$ occur by the fifth day, which decreases hereafter to about $20 \mathrm{~m} \mathrm{~s}^{-1}$ by 10 days of model integration (Fig. 1b). A strong temperature gradient zone that circumscribes the continent is also well developed within the $24 \mathrm{~h}$ simulation (Fig. 5a).

By the third day, four cyclonic circulations had formed far north from the coast (Fig. 3b). The origin of these features may be questionable since they formed near the corners of the model domain; however, note that they were already suggested since the first day. In addition, as the integration proceeds the temperature gradient intensifies in the areas where the maximum katabatic winds took place (see the arrows in Fig. 5b). After the fifth day, the strong temperature gradient zone became baroclinically unstable and created other four cyclonic circulations. These simulated perturbations have characteristics which are very similar to those observed in the real world, and they are located near the zones where the katabatic winds converge. In the mean time, the original four new cyclones had moved poleward near the areas where the meridional temperature gradient had also intensified, near maximum katabatic winds. Note that the cyclonic centers show a westward displacement (Fig. 3).

Intriguing is that at the second sigma level (about $300 \mathrm{~m}$ ), the offshore cyclonic circulations were accompanied by anticyclonic centers just inland over the continent (Fig. 2). This coupling of the offshore cyclonic and inland anticyclonic circulation does not extend above the third sigma level. This suggests the existence of a mesoscale north-south circulation where one branch is composed of the descending near-surface katabatic winds, convergence offshore that induces the cyclonic circulation with upward motions, an inland branch in the lower troposphere (below $1000 \mathrm{~m}$ : third sigma level) and sinking motion above the anticyclonic features (Fig. 6). These circulations are embedded within the large-scale meridional circulation of Antarctica (see Parish \& Bromwich, 1991; Parish, 1992). The large-scale circulation is composed of the near-surface continental-scale katabatic drainage that diverges from the plateau, a strong convergence with rising motion that takes place just offshore of the continent, and a return branch in the middle and high troposphere toward the high plateau where sinking motion closes the meridional circulation. Fig. 6 schematically 

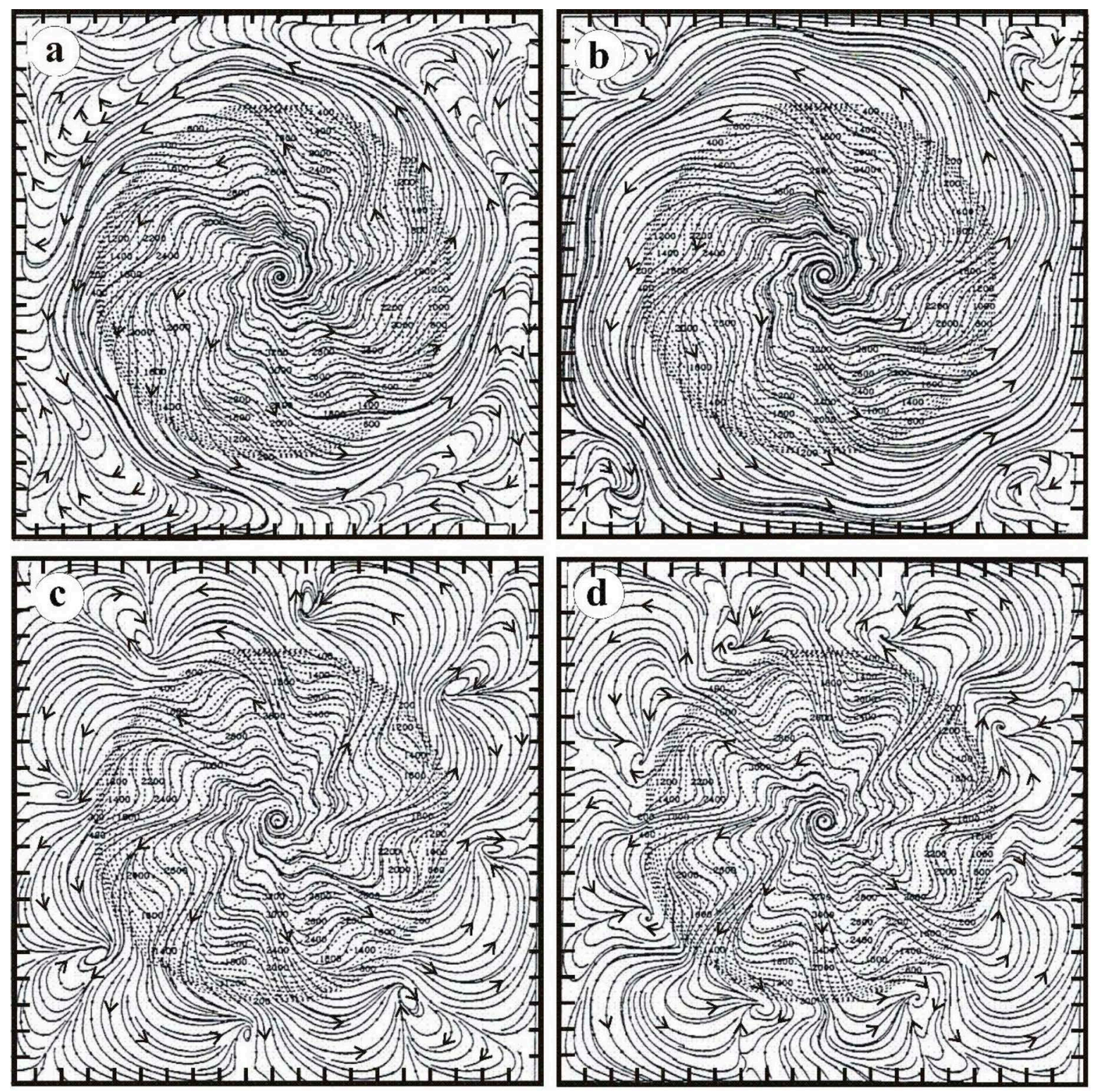

Fig. 3. Streamlines at the first sigma level after the (a) first, (b) third, (c) sixth and (d) eight days of model integration using an idealized Antarctic model.

depicts the meridional mesoscale and large-scale meridional circulations adapted from Parish and Bromwich (1991). This picture highly simplifies the complexity of the circulation over the South Polar Region.

\section{DISCUSSION AND CONCLUSIONS}

Numerical simulations of subsynoptic cyclogenesis around an idealized Antarctic continent were conducted using a simplified threedimensional numerical model. The model domain included a dome surrounded by open ocean, centered at the South Pole. The dome represents a circular Antarctic continent with a plateau of 3800 $\mathrm{m}$ elevation at its center and steep coastal margin. Eight topographic longitudinal troughs dissect the dome to simulate the real features of Antarctica 




Fig. 4. Same as Figure 3, but for wind sped (contour interval $5 \mathrm{~ms}^{-1}$ ).

that play an important role in driving the katabatic winds. The model rapidly simulated the continental near-surface katabatic winds, whose intensities are similar to those observed in Antarctica (Parish and Bromwich, 1987, 1991; Bromwich, 1989; Bromwich et al. 1990). Also, the model resolved cyclogenesis around the margin of the continent, near the katabatic confluence zones. After the fifth days, eight subsynoptic-scale cyclonic features have developed around the simulated continent, offshore the topographic troughs. These cyclonic centers show a westward displacement, similar movement has been shown by observational studies around Antarctica carried out by Carrasco et al. (2003), Pezza et al. (2016), Verezemskaya et al. (2017), and others. A near-surface strong temperature gradient developed near the katabatic confluence zone, and near where the subsynoptic low pressure developed and the streamlines spiral to form a cyclonic circulation. Close examination suggests stronger wind speed at the adge of the low pressure, which concurs with Verezemskaya et al. (2017) 


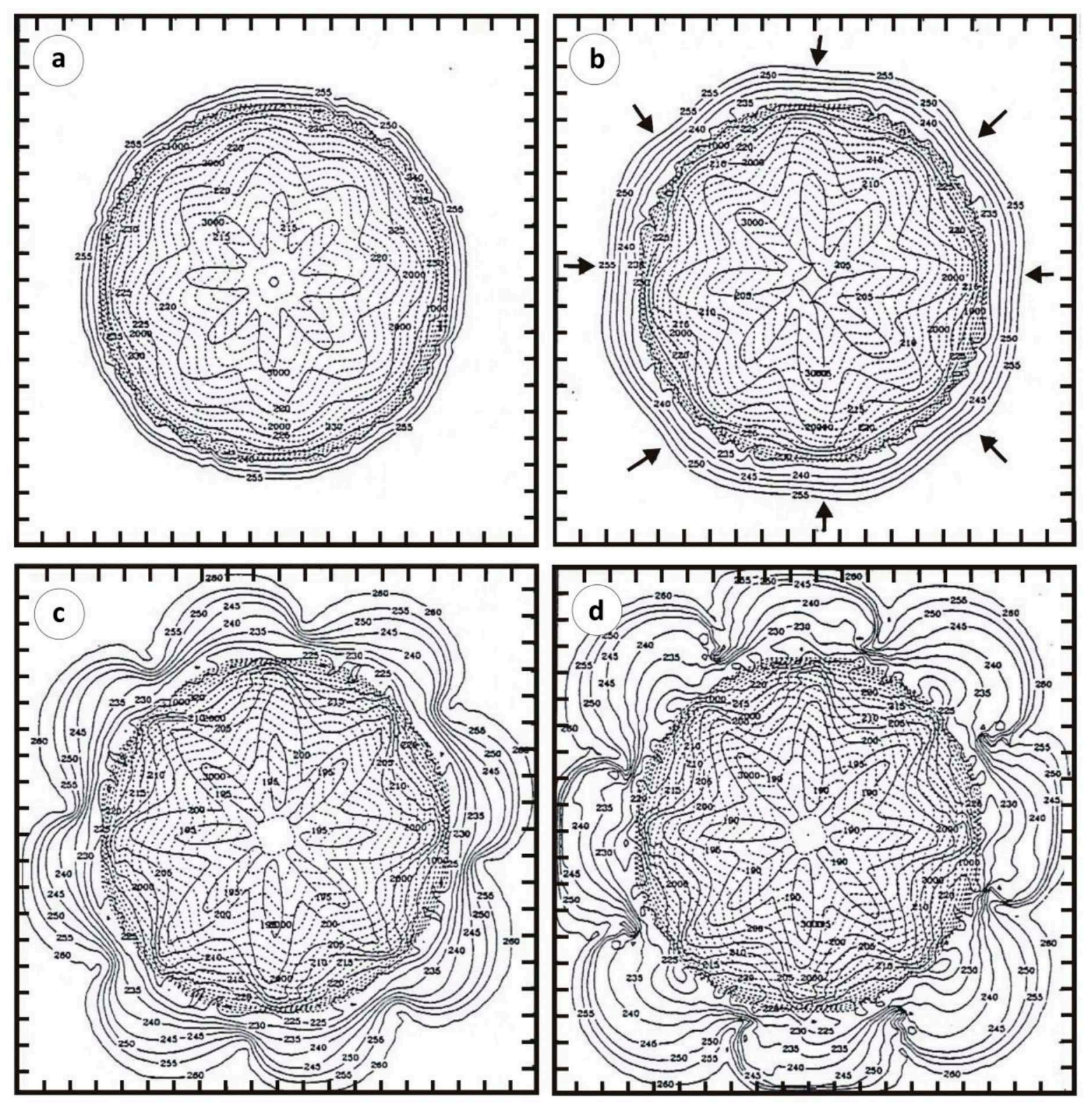

Fig. 5. Same as Figure 3, but for temperature (contour interval $5 \mathrm{~K}$ ). Arrows indicate areas where enhanced meridional temperature gradient will take place.

observations. The main role of the topography is that orography troughs act as convergence zone for the descending katabatic windflow, this cold air mass interacts with warmer environment once arriving to the ocean adjacent to the coast.

Because the model in principle simulates the katabatic drainage over the continent, the formation of these cyclones are caused by the interaction between the katabatic airflow and the surrounding near-surface tropospheric air. The real climate of Antarctica shows a ring of large scale low pressure centers around the continent (circumpolar trough), these centers are beleaved to be areas of large synoptic and subsynoptic cyclonic activity. The model did not include a sea-ice pack surrounding the continent, so it did not simulate subsynoptic cyclone formation at the edge of the ice pack, i.e., further north from the coastal 
continent. Therefore, the simulated centers only suggest that the katabatic airflows play, at least in part, a role in cyclogenesis in this belt, contributing in this cyclonic activity and in building up the climatological low pressure centers.

The second sigma level (just above the BL) also simulated the eight cyclonic circulations but they were not resolved from the third level upward, indicating that these are shallow features (they have a depth of at least $300 \mathrm{~m}$, but under $1000 \mathrm{~m}$ ). Also, the streamlines at the second sigma level revealed a more complex circulation, with subsynoptic-scale anticyclonic features to the south (over the continent) of the cyclonic ones. This might suggest a subsynoptic meriodional circulation (Fig. 6) around the coastal margin of the simulated Antarctic continent. From the third sigma level up to the sixth, the model simulated the westerly circulation that dominates the southern latitudes, with a vortex centered over the South Pole. This suggests that the origin and initial development of the polar vortex is due to the radiative cooling of the Antarctic continent. This concurs with the fact that the real polar vortex intensifies during the winter, and weakens in summer.

The strong temperature gradient zones or front-like features are areas of baroclinic inestability. Walsh et al. (2000, Walsh et al. 2000 hereafter) used a two-layer sigma-level model for baroclinicity simulation around Antarctica, but resolving only for synoptic-scale features. The model was first applied to the ECMWF (European Center for Medium Range Forecasts) analyses averaged over the winter (May-October), for obtaining "observed" cyclogenesis over the Southern Hemisphere; and then, it was used to diagnose baroclinicity from the output of a series of winter GCM (using the Australian Global Climate Model) experiments with varying height of Antarctica to evaluate the influence of changing topography on baroclinicity in the surrounding region. According with Walsh et al. (2000), as the Antarctic topography was decreased (July experiments), the circumpolar trough gradually becomes weaker and broader and less defined, ending for the case of no Antarctic continent, with two main lows; one partially over the coast of East Antarctica and the other in the southwestern Pacific Ocean adjacent to the coast of West Antarctica. For "real" simulated continent, they found a band of maximum predicted incipient instability to the north of the circumpolar trough, which is in general agreement with the observed ECMWF cyclogenesis and with the ones described by Sinclear (1995) and Jones and Simmonds (1993), although Turner et al. (1998) questioned the results of these studies due to that they probably underestimated the cyclogenesis activity. Also, the simulation without topography showed some incipient instability over these two regions of Antarctica suggesting that cyclone formation and intensification would be possible, although the main regions of intensification is more likely to occur

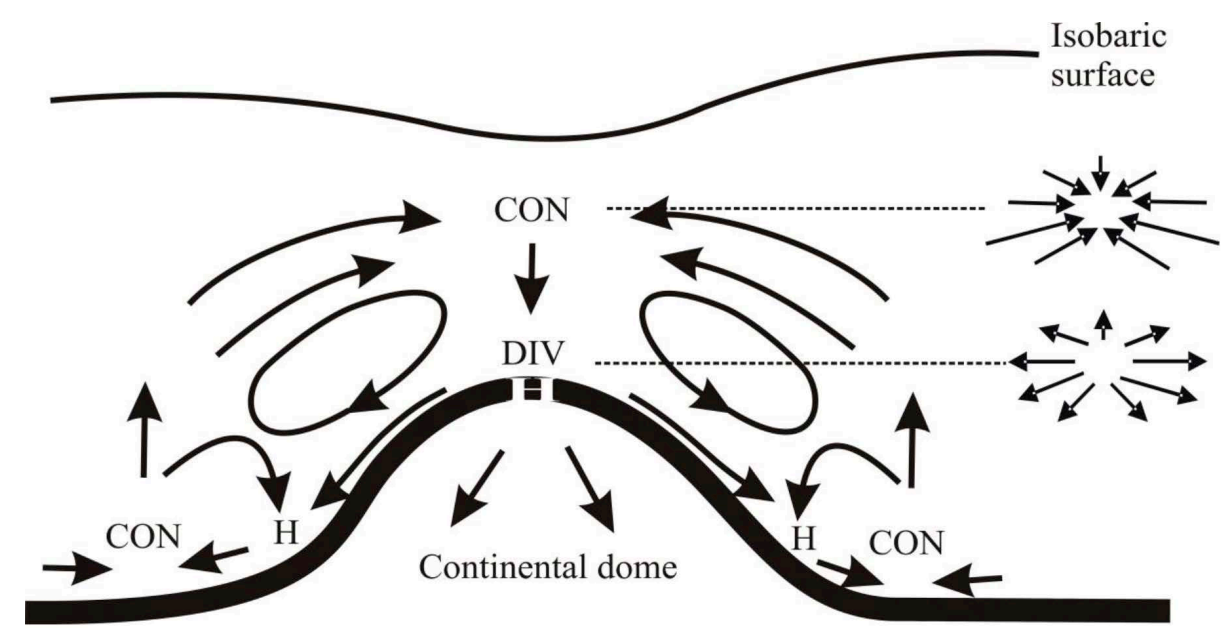

Fig. 6. Schematic depiction of the meridional regional and large circulations over Antarctica (adapted from Parish \& Bromwich, 1991). CON: convergence, DIV: divergence, H: high pressure. 
equatorward of the continent. Walsh et al. (2000) results indicated little or no cyclogenesis over real Antarctica, but as the topography is decreased, baroclinicity over the continent can occur.

Walsh et al. (2000) experiment resolved that the low pressure centers of the circumpolar trough seem to be closed to the major embayments of the Antarctic continent (Ross Sea/Ross Ice Shelf, Weddel Sea/Ronne Ice Shelf, Amery Ice Shelf) and can be due to mechanical eddy formation as Baines and Fraedrich (1989) explained. Although the climatological centers as modeled by the ECMWF analyses are not as closely related to the embayments, due probably to the sprectral smoothing of the GCM topography, they suggested that mechanical eddy formation has at least a partial role in the location and maintenance of the circumpolar trough (Walsh et al. 2000). Even though, Walsh et al. (2000) results are for larger scale circulation and used a "real" Antarctic continent than the simulation presented here, some similarities can be explored. Both resolved cyclogenesis offshore of the coastal Antarctic continent, but the subsynoptic PWmodel simulated the cyclogenesis areas nearer to the coast (due to katabatic airflow and no sea ice pack), while the Walsh et al. (2000) simulated further to the north in the open ocean. Both models showed low pressure centers adjacent to the orographic troughs (for PWmodel) or major embayments (for Walsh et al. 2000) where descending katabatic airflow converge. Non cyclogenesis was resolved by the PWmodel over the ideal dome continent, nor the Walsh et al. (2000) for the simulated Antarctic topography.

\section{AKNOWLEDGEMENT}

To David H. Bromwich for all the advices and correction of the original manuscript (a Thesis Chapter of the author) and Thomas R. Parish for providing the numeral model. Partially supported by the Fondecyt project $N^{\circ} 1151034$ for updating and rewriting the manuscript.

\section{APPENDIX 1}

Following Anthes and Warner (1978), the horizontal momentum equations expressed in flux form were:

$$
\begin{aligned}
& \frac{\partial p^{*} u}{\partial t}=-\frac{\partial p^{*} u u}{\partial x}-\frac{\partial p^{*} u v}{\partial y}-\frac{\partial p^{*} u \dot{\sigma}}{\partial \sigma}-p^{*}\left[\frac{R T}{\left(p^{*}+p_{t} / \sigma\right)} \frac{\partial p^{*}}{\partial x}+\frac{\partial \phi}{\partial x}\right]+p^{*} f v+F_{u}+H_{u} \\
& \frac{\partial p^{*} v}{\partial t}=-\frac{\partial p^{*} v u}{\partial x}-\frac{\partial p^{*} v v}{\partial y}-\frac{\partial p^{*} v \dot{\sigma}}{\partial \sigma}-p^{*}\left[\frac{R T}{\left(p^{*}+p_{t} / \sigma\right)} \frac{\partial p^{*}}{\partial y}+\frac{\partial \phi}{\partial y}\right]-p^{*} f u+F_{v}+H_{v}
\end{aligned}
$$

and the continuity equation was:

$$
\frac{\partial p^{*}}{\partial t}=\frac{\partial p^{*} u}{\partial x}-\frac{\partial p^{*} v}{\partial y}-\frac{\partial p^{*} \dot{\sigma}}{\partial \sigma}
$$

The thermodynamic equation written in an advective form was:

$$
\frac{\partial T}{\partial t}=-u \frac{\partial T}{\partial x}-v \frac{\partial T}{\partial y}-\dot{\sigma} \frac{\partial T}{\partial \sigma}+\frac{R T \omega}{c_{p}\left(p^{*} \sigma+p_{t}\right)}+\frac{Q}{c_{p}}+F_{t}+H_{t}
$$

The advective form of the thermodynamic equation was shown to be slightly more stable in the 
numerical experiments conducted by Seaman and Anthes (1980). To close the system, the hydrostatic equation was expressed as:

$$
\frac{\partial \phi}{\partial \ln \left(\sigma+p_{t} / p^{*}\right.}=-R
$$

$p:$ pressure

$p^{*}: p_{s}-p_{t}$

$p_{s}$ : surface pressure

$p_{t}$ : pressure at top of model

$u$ : zonal wind speed relative to earth in $\mathrm{x}$ direction

$v$ : merional wind speed relative to earth in y direction

$\omega$ : vertical wind speed relative to earth in $z$ direction

$R$ : gas constant for dry air

$c_{p}$ : specific heat of dry air at constant pressure

$T$ : air temperature $(\mathrm{K})$

$f$ : Coriolis parameter

$\sigma$ : vertical coordinate $\left[=\left(p-p_{t}\right) /\left(p_{\mathrm{s}}-p_{t}\right)\right]$

$\dot{\sigma}: d \sigma^{\prime} d t$

$\phi$ : geopotential

$F$ : frictional acceleration

$H$ : sensible heat flux

$Q$ : diabatic heating per unit mass

\section{REFERENCES}

Anthes, R. A., \& Warner, T. T. (1978). The development of hydrodynamics models suitable for air pollution and other mesometeorological studies. Monthly Weather Review, 106, 1045-1078.

Baines, P. G., \& Fraedrich, K. (1989). Topographic effects on the mean tropospheric flow patterns around Antarctica. Journal of Atmospheric Sciences, 46(22), 34013415.

Bromwich, D. H. (1989). Subsynopticscale cyclone developments in the Ross Sea sector of the Antarctic. In P. F. Twitchell, E. A.
Rasmussen, and K. L. Davidson (Eds.) Polar and Arctic Lows (pp. 331345). Virginia: A. Deepak Publishing, Hampton.

Bromwich, D. H. (1989). An extraordinary katabatic wind regime at Terra Nova Bay, Antarctica. Monthly Weather Review, 117, 688-695,

Bromwich, D. H., Parish, T. R., \& Zorman, C.A., (1990). The confluence zone of the intense katabatic winds at Terra Nova Bay, Antarctica as derived from airborne sastrugi surveys and mesoscale numerical modeling. Journal Geophysical Research, 95, 54955509.

Bromwich, D. H., Otieno, F. O., Hines, K. M., 
Manning, K. W., \& Shilo, E. (2013). Comprehensive evaluation of polar weather research and forecasting performance in the Antarctic. Journal Geophysical Research, 118, 274-292.

Carrasco, J. F., \& Bromwich, D. H. (1993). Mesoscale cyclogenesis dynamics over the southwestern Ross Sea, Antarctica. Journal of Geophysical Research, 98, 1297312995.

Carrasco, J. F., \& Bromwich, D. H. (1996). Mesoscale cyclone activity near Terra Nova Bay and Byrd Glacier, Antarctica during 1991. The Global Atmosphere and Ocean System, 5, 43-72.

Carrasco, J. F., Bromwich, D. H., \& Monoghan, A.J. (2003). Distribution and characteristics of mesoscale cyclones in the Antarctic: Ross Sea eastward to the Weddell Sea. Monthly Weather Review, 131, 289-301.

Heinemann, G. (1996). A wintertime polar low over the eastern Weddell Sea (Antarctica): A study with AVHRR, TOVS, SSM/I and conventional data. Meteorology Atmosphere Physics, 58, 83-102.

Heinemann, G., \& Klein, T. (2003). Simulation of topographically forced mesocyclones in the Weddell Sea and the Ross Sea region of Antarctica. Monthly Weather Review, 131, 302-316.

Jones, D. A., \& Simmonds, I. (1993). A climatology of Southern Hemisphere extratropical cyclones. Climate Dynamics, 9, 131-145.

Klein, T., \& Heinemann, G. (2001). On the forcing mechanisms of mesocyclones in the eastern Weddell Sea region, Antarctica: Process studies using a mesoscale numerical model. Meteorologische Zeitschrift, 10, 113-122.

Parish, T. R. (1992). On the interaction between Antarctic katabatic winds and tropospheric motions in the high southern latitudes. Australian Meteorological Magazine, 40, 149-167.

Parish, T. R., \& Bromwich, D. H. (1987). The surface windfield over the Antarctic ice sheets. Nature, 328, 5154.

Parish, T. R., \& Bromwich, D. H. (1991). Continental-scale simulation of the Antarctic katabatic wind regime. Journal of Climate, 4(2), 135-146.

Parish, T. R., \& Waight, K. T. (1987). The forcing of Antarctic katabatic winds. Monthly Weather Review, 115, 2214-2226.

Pezza, A., Sadler, K., Uotila, P., Vihma, T., Mesquita, M. D. S., \& Reid, P. (2015). Southern Hemisphere strong polar mesoscale cyclones in high-resolution datasets. Climate Dynamics, DOI 10.1007/ s00382-015-2925-2.

Powers, J. G., Monaghan, A. J., Cayette, A. M., Bromwich, D. H., Kuo, Y.-H., \&. Manning, K. W. (2003). Real-time mesoscale modeling over Antarctica: The Antarctic Mesoscale Prediction System (AMPS). Bulletin American Meteorological Society, 84, 1533-1545.

Seaman, N. L., \& R. Anthes, A. (1981). A mesoscale semi-implicit numerical model. Quarterly Journal Royal of the Meteorololgical Society, 107, 167-190.

Sinclair, M. R. (1995). A climatology of cyclogenesis for the Southern Hemisphere. Monthly Weather Review, 123, 1601-1619.

Turner, J, Lachlan-Cope, T. A., Warren, D. E., \& Duncan, C. N. (1993). A mesoscale vortex over Halley Station, Antarctica Monthly Weather Review, 121, 1317-1336.

Turner, J., Corcoran, G., Cummins, S., LachlanCope, T., \& Leonard, S. (1996). Seasonal variability of mesocyclone activity in the Bellingshausen/Weddell region of Antarctica. The Global Atmosphere and Ocean System, 5, 73-97.

Turner, J., Marshall, G. J., \& Lachlan-Cope, T.A., (1998). Analysis of synoptic-scale low pressure systems within the Antarctic Peninsula sector of the circumpolar trough. International Journal of Climatology, 18(3). 253-280.

Uotila, P., Vihma T., Pezza, A. B., Simmonds, I., Keay K., \& Lynch, A. H. (2011). Relationships between Antarctic cyclones and surface conditions as derived from highresolution numerical weather prediction data. Journal of Geophysical Research, 116, D07109.

Verezemskaya, P., Tilinina, N., Gulev, S., Renfrew, 
I. A., \& Lazzara, M., (2017). Southern Ocean mesocyclones and polar lows from manually tracked satellite mosaics. Geophysical Research Letters, 44, doi:10.1002/2017GL074053.
Walsh, K. J. E., Simmonds, I., \& Collier, M., (2000). Sigma-coordinate calculation of topographically forced baroclinicity around Antarctica. Dynamics of Atmospheres and Oceans, 33(1), 1-29. 